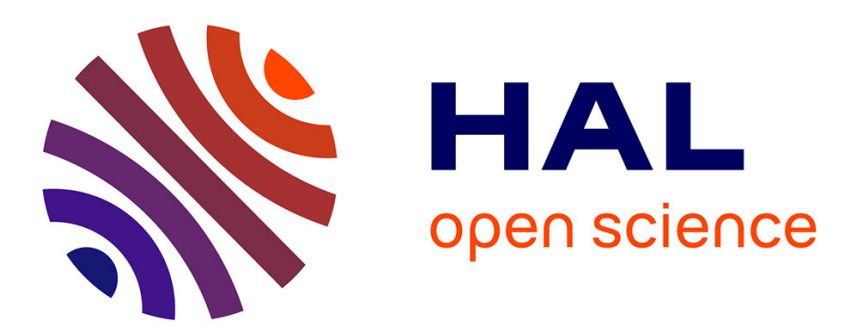

\title{
Vibrational properties of silicates: A cluster model able to reproduce the effect of "SiO4" polymerization on Raman intensities
}

\author{
Vanessa Labet, Philippe Colomban
}

\section{- To cite this version:}

Vanessa Labet, Philippe Colomban. Vibrational properties of silicates: A cluster model able to reproduce the effect of "SiO4" polymerization on Raman intensities. Journal of Non-Crystalline Solids, 2013, 370, pp.10-17. 10.1016/j.jnoncrysol.2013.03.025 . hal-00812191

\section{HAL Id: hal-00812191 \\ https://hal.sorbonne-universite.fr/hal-00812191}

Submitted on 12 Apr 2013

HAL is a multi-disciplinary open access archive for the deposit and dissemination of scientific research documents, whether they are published or not. The documents may come from teaching and research institutions in France or abroad, or from public or private research centers.
L'archive ouverte pluridisciplinaire HAL, est destinée au dépôt et à la diffusion de documents scientifiques de niveau recherche, publiés ou non, émanant des établissements d'enseignement et de recherche français ou étrangers, des laboratoires publics ou privés. 


\title{
Vibrational properties of silicates: A cluster model able to reproduce the effect of " $\mathrm{SiO}_{4}$ " polymerization on Raman intensities
}

\author{
Vanessa Labet ${ }^{a, b}$ and Philippe Colomban ${ }^{a, b}$ \\ ${ }^{a}$ UPMC Univ. Paris 06, UMR 7075, Laboratoire de Dynamique, Interactions et Réactivité, \\ 75005 Paris, France \\ ${ }^{b}$ CNRS, UMR 7075, LADIR, 75005 Paris, France \\ vanessa.labet@upmc.fr; philippe.colomban@upmc.fr
}

\section{Published version :}

http://dx.doi.org/10.1016/j.jnoncrysol.2013.03.025 (Journal of Non-Crystalline Solids)

\section{Corresponding author:}

Vanessa Labet

Laboratoire de Dynamique, Interactions et Réactivité (LADIR) - UMR 7075 CNRS/UPMC Université Pierre et Marie Curie

Case Courrier 49, Bât. F74

4, place Jussieu

F-75252 Paris Cedex 05, France

Tel : +331 44273024

vanessa.labet@upmc.fr 


\begin{abstract}
An ensemble of ten silicate clusters is examined using quantum chemical calculations (Density Functional Theory) as a potential model to study the effect of polymerization of the $\mathrm{SiO}_{4}$ units on Raman intensities of silicates (crystalline and amorphous). Quite originally, instead of saturating non-bridging oxygen (NBO) with hydrogen atoms as generally found in the literature for similar approaches, NBOs, which hold a negative charge if not saturated, have been substituted by isoelectronic fluorines whose mass is corrected in normal mode calculations to be equal to that of an oxygen. By adjusting the number of fluorines per silicon, the different $Q_{n}$ coordination types characterizing the different classes of silicates are modeled. The relevance of this ensemble of clusters as a model to study the effect of polymerization on Raman intensities is established in several steps, the most important one being the qualitative reproduction of evolution of the Ip polymerization index with the number of bridging oxygen per silicon.
\end{abstract}

\title{
Keywords
}

Silicates, Glass, Raman intensity, DFT, cluster model 


\section{Introduction}

Silicates are all built from " $\mathrm{SiO}_{4}$ " tetrahedral units based on the $\mathrm{Si}-\mathrm{O}$ bond, one of the strongest between an element $\mathrm{A}$ and oxygen $\mathrm{O}$ with its $452 \mathrm{~kJ} / \mathrm{mol}$ (see Table $\mathrm{S} 1$ in Supplementary Information for comparison with other selected A-O bonds, typical of inorganic oxides) [1]. Due to the electronegativity difference between silicon $\left(\chi_{\mathrm{Si}}=1.9\right.$ in the Pauling scale) and oxygen $\left(\chi_{\mathrm{O}}=3.4\right.$ in the Pauling scale) Si-O bonds can be considered as half covalent - half ionic; they are typical examples of very polarized covalent bonds, also referred to as ionocovalent bonds. Interesting discussions can be found in the literature about the relevance of considering such bonds as covalent or ionic [2,3]. In many silicates, part of the silicon ions are substituted by aluminum ions leading to Al-O bonds, characterized by a lower covalent character, due to higher electropositivity of $\mathrm{Al}$ compared to $\mathrm{Si}\left(\chi_{\mathrm{Al}}=1.6\right.$ in the Pauling scale).

All applications in science, art and technology of glasses, glazes and enamels consist of a controlled modification of the three dimensional Si-O network by partial replacement of silicon atoms by other electropositive $\mathrm{M}$ elements leading to less- or non-covalent $\mathrm{M}-\mathrm{O}$ bonds. The number of strong bridges between two structural units then decreases, as the connectivity of the Si-O network. Indeed, the introduction in silica of $\mathrm{M}_{\mathrm{x}} \mathrm{O}_{\mathrm{y}}$ metallic oxides involving very electropositive $\mathrm{M}$ cations (typically alkaline or alkaline earth cations) induces depolymerization of the silicon-oxygen network to a certain extent, some connections between the corner-sharing tetrahedra needing to be broken to take charge of the positive charge of the metallic cation. As such, the melting temperature can be adjusted from $\sim 1500$

to $\sim 500{ }^{\circ} \mathrm{C}$. Many other physical and chemical properties related to density and network connectivity (e.g. thermal expansion, chemical resistance, color, etc) are modified simultaneously. 
Depending on $(i)$ the relative amount of $\mathrm{SiO}_{2}$ and $\mathrm{M}_{\mathrm{x}} \mathrm{O}_{\mathrm{y}}$ and (ii) the formal charge of the $\mathrm{M}$ cation, the number of other tetrahedra to which a given " $\mathrm{SiO}_{4}$ "-tetrahedron is connected can be reduced from 4 to 3, 2, 1 or even 0 . In other words, the number of bridging oxygen atoms $(\mathrm{BO})$ per silicon one can be reduced from 4 to 0 while at the same time the number of non-bridging oxygen atoms (NBO) increases from 0 to 4 . In this latter case the silicate part of the material consists of isolated $\mathrm{SiO}_{4}{ }^{4-}$ anions; the $\mathrm{Si}-\mathrm{O}$ network is said to be completely depolymerized. A convenient $Q_{n}$ nomenclature where $n$ denotes the number of BO per silicon has been developed in parallel to the classification of minerals into neso-, soro-, ino-, cyclo-, phyllo- and tektosilicates (structural features reported in Table S2) to characterize the coordination of silicon atoms [4].

In these different classes of silicates, the " $\mathrm{SiO}_{4}$ " tetrahedron remains remarkably constant, with intra-tetrahedron $\mathrm{O}-\mathrm{Si}-\mathrm{O}$ angles close to $109.5^{\circ}$. On the contrary, the Si-O-Si angles between two tetrahedra are very flexible due to the flatness of the associated potential energy surface [5]. This flexibility is at the origin of the breakdown of structural order at long distance and to the appearance of amorphous states of silicates. Indeed, though the intertetrahedra $\mathrm{Si}-\mathrm{O}-\mathrm{Si}$ angle is fixed to $144^{\circ}$ in $\alpha$-quartz -- the thermodynamically most stable polymorph of crystalline silica at room temperature and atmospheric pressure, it can vary from $120^{\circ}$ to $180^{\circ}$ in silicate glasses [6-8]. It also has to be noted that a silicate glass is likely to be characterized by several $Q_{n}$ coordination types for its silicon nuclei.

If X-ray diffraction has revealed very useful to solve the structure of crystalline silicates [9], ${ }^{29} \mathrm{Si}$ NMR [10] and Raman spectroscopy [11] are more appropriate to gain information on the short-range structure of amorphous silicates. Raman spectra of these latter are characterized by two main bands: one centered at $500 \mathrm{~cm}^{-1}$ originating from (generally degenerated) intra-tetrahedral $\mathrm{O}-\mathrm{Si}-\mathrm{O}$ angle bending and one centered at $1000 \mathrm{~cm}^{-1}$, attributed 
to (symmetric) Si-O bond stretching modes [12-18]. The band centered at $1000 \mathrm{~cm}^{-1}$ can be decomposed as the sum of 5 bands -- one for each $Q_{n}$ component -- whose center wavenumbers increase as $n$ increases: $800-850 \mathrm{~cm}^{-1}$ for $Q_{0}, 950 \mathrm{~cm}^{-1}$ for $Q_{1}, 1050-1100 \mathrm{~cm}^{-1}$ for $Q_{2}, 1100 \mathrm{~cm}^{-1}$ for $Q_{3}$ and $1150-1250 \mathrm{~cm}^{-1}$ for $Q_{4}$ [11,19-22]. The interest of this modeling is to remain valid for all silicates. It was proposed that two phenomena were indeed explaining the trend in the evolution of the wavenumbers: the $Q_{n}$ coordination type of " $\mathrm{SiO}_{4}$ " tetrahedra from one hand but also the number and nature of rings in which they are involved [23]. In a similar way, the band centered at $500 \mathrm{~cm}^{-1}$ can also be decomposed into 5 bands, (more generally $2 \times 5$ because of the $\mathrm{E}$ character of the strongest bending mode), but the correlation between position and $Q_{n}$ coordination type is less obvious as wavenumbers characteristic of bending modes appear to be very sensitive to the value of the Si-O-Si angles $[11,19,24]$

Analysis of the stretching band envelope of a given silicate can then provide useful information about its microstructure. It is interesting to notice that as such it exploits the differences induced by different $Q_{n}$ coordination types on the Si-O bond strengths. But besides this mechanical information, Raman spectroscopy can also give electrical information on the bonds as soon as one becomes interested in band intensities rather than wavenumbers only.

The evolution of Raman intensities with the type of the silicon-oxygen network was first studied by White and coworkers [25]. Later on, it was proposed by Colomban [12, 13] that the relative intensities of the bending and stretching bands can provide good indication of the degree of polymerization of a silicate because of modification of the partial charge of oxygen atoms involved in the Si-O bonds [26]. Based on this idea, a polymerization index (Ip) was defined as the ratio of the area of the bending band at $500 \mathrm{~cm}^{-1}$ and the stretching one at $1000 \mathrm{~cm}^{-1}$ : 
$I p=\frac{A_{500}}{A_{1000}}$

The efficiency of the Ip index has been demonstrated empirically by the study of amorphous and crystalline silicates of known composition. Low degrees of polymerization are characterized by a low Ip and high degrees of polymerization by a high Ip as illustrated on Figure 1 where is shown on one hand the evolution of Ip in a series of glasses and enamels (amorphous silicates, Figure 1.a) and on the other hand the evolution of Ip in a series of crystalline silicates covering coordination types for $\mathrm{Si}$ atoms from $\mathrm{Q}_{0}$ to $\mathrm{Q}_{4}$ (Figure 1.b).
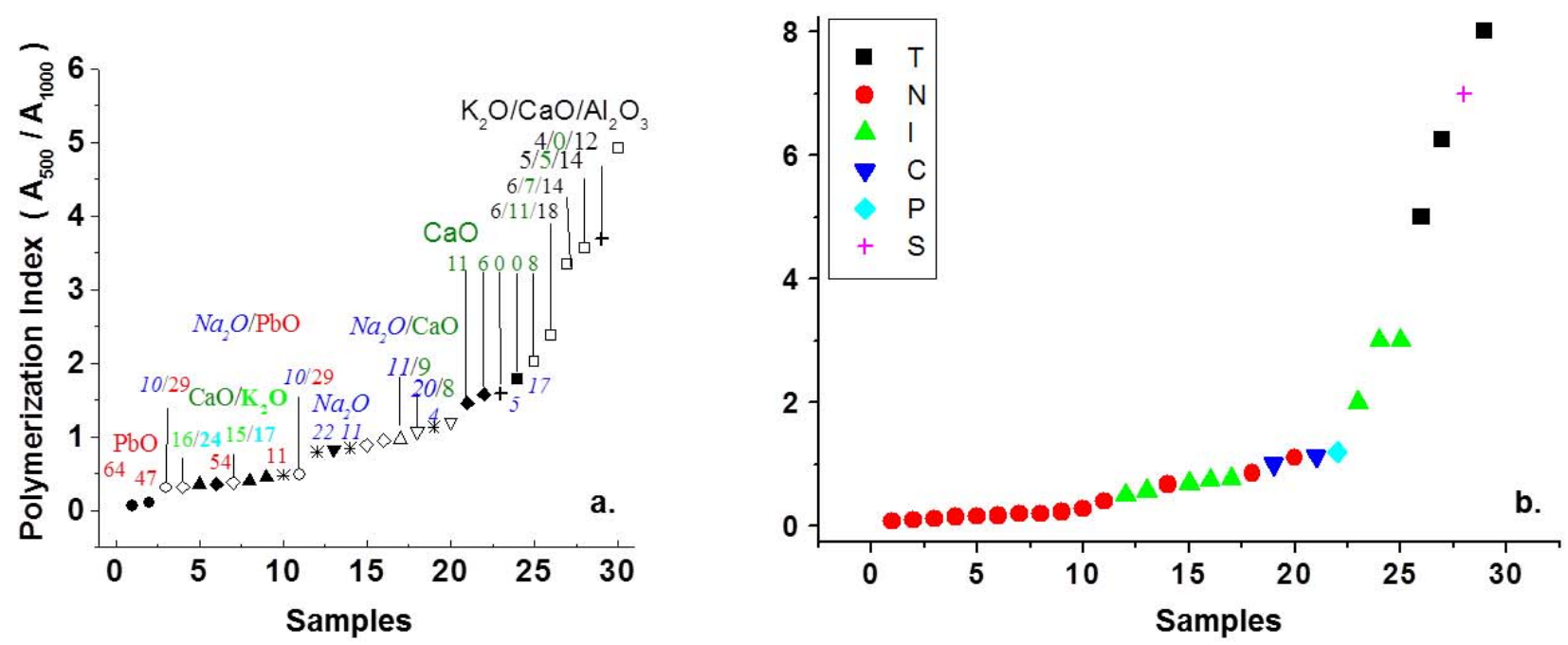

Fig. 1. Empirical evolution of the polymerization index Ip for series of amorphous (a, see details in ref [27]) and crystalline (b, see details in ref [28]) aluminosilicates; in (a) the main fluxing oxides and their molar ratio are given; in (b) the different mineral types are given (T: tektosilicates, $N$ : nesosilicates, I: inosilicate, $C$ : cyclosilicate, $P$ : phyllosilicate, $S$ : sorosilicates). Numbers in the X-axis indicate the label of each sample in the series of amorphous (a) and crystalline (b) aluminosilicates.

Despite its practical efficiency [27-33], the Ip index is currently lacking some theoretical support which would comfort spectroscopists in its use by rationalizing its evolution. One way to better understand why the Ip index evolves as it does with polymerization of the " $\mathrm{SiO}_{4}$ " units is to analyze the phenomenon in numerical experiments, i.e. using quantum chemical calculations. This needs beforehand construction of models 
whose vibrational properties will then be studied computationally. The objective of the present article is to propose and test structural models for silicates, suitable to study the influence of " $\mathrm{SiO}_{4}$ " polymerization on Raman intensities of silicates. In the next section, the strategy chosen to construct the models will be presented. Then, the computational methodology used to study their structural and electronic properties will be specified in section 3, together with the tools used for the analysis of their vibrational characteristics. Then, in section 4, the different elements leading to validation of the models to study the effect of polymerization on the Ip index will be given.

\section{Construction of a structural model}

\subsection{Discrete versus periodic}

Two main kinds of structural models are used in numerical experiments at the atomic scale to mimic solids (and surfaces): cluster models (nonperiodic) and models based of the infinite repetition of a unit cell (periodic) [34, 35].

Early on, silicate molecules or clusters have been used as models to study structural and electronic properties of solid silicates (either crystalline or amorphous) [36, 37], as well as their vibrational properties $[23,38]$, based on the observation that for a same close environment --let's say the same first coordination polyhedron -- a given chemical bond has the same characteristics, either in an isolated molecule or in a crystal structure [39-42]. Indeed, if obviously the length of a given chemical bond -- and its associated bond strength by virtue of the empirical Badger's rule [43-45] -- depends on its chemical environment, what governs bond length and angle variations is relatively short ranged. Based on this same idea, ab initio calculations on silicate molecules / clusters have been used to construct force fields / interatomic potentials used then in molecular-dynamics simulations to study the structural and 
vibrational characteristics of silica-based materials, either crystalline [46-48] or amorphous $[49,50]$

Currently, the vibrational properties of crystalline silicates are studied in numerical experiments using preferentially periodic models. This approach has brought useful aid in the identification of silicated phases, simply by comparison of experimental and computed vibrational spectra [51-56].

But for the vibrational properties of amorphous silicates, both the cluster and the periodic approaches compete and complement each other [57-61]. Elaborated structural models for amorphous silicates have been constructed from classical and ab initio (CarParinello) molecular dynamics experiments (periodic models with large unit cells) [62-65]. These have the advantage to show a statistical representation of the structural features of the materials from which it becomes possible to obtain realistic vibrational properties. Ab initio calculations on cluster models have also been used to study the vibrational signature of specific structural features, such as rings, in silicates glasses [66] and then gain information about their local structure. This approach, obviously valid for the study of other glassy materials, has also been applied, among other, to arsenic sulfides [67], boron oxides [68], and carbon nitrides [69].

As mentioned earlier, in this work, the objective is to construct a model suitable to study the effect of the degree of polymerization of the $\mathrm{SiO}_{4}$ units on the Raman intensities of silicates. As such, rather than a single elaborated model encompassing the whole structural complexity of a real glass, it was decided to consider an ensemble of very simple structures whose different individuals capture the essence of the different $Q_{n}$ coordination types. In a chemical system, the Raman intensity associated with a given normal mode comes from the system polarizability response to a modification of the geometry according to the normal 
atomic displacements. According to the Bond Polarizability Model [70-72], polarizability of a molecular system can be seen as the sum of its bond polarizabilities. Thus Raman intensities result from modifications of bond lengths and valence angles according to normal atomic displacements, phenomena, which are short-ranged. Thus the simple structures capturing the different $Q_{n}$ coordination types could have been either the infinite repetition of small unit cells or silicate clusters. Quite arbitrary, it was decided to consider the latter approach. It has the advantage to be very easy to implement. In compensation, it will be difficult to model simply $Q_{4}$ coordination with this approach. We will come back to this later.

\section{2. $-\mathrm{F}$ versus $-\mathrm{O}^{-}$}

Except in the case of silica, the Si-O network of silicates is inherently negatively charged: each non-bridging oxygen atom induces one negative charge. This is problematic in a cluster approach since small multiply charged anions (MCA) are not stable electronically due to strong Coulomb repulsion [73-74]. It means that for example it is not conceivable to consider an isolated $\mathrm{SiO}_{4}{ }^{4-}$ anion as a model for nesosilicates. Surely, the stability of MCAs increases as their size increases too, nonetheless it is not probably more appropriate to consider $\mathrm{Si}_{2} \mathrm{O}_{7}{ }^{6-}$ anion as a model for sorosilicates.

To overcome this difficulty, people who have used cluster models to mimic silicates have very often saturated the non-bridging oxygen atoms with hydrogen atoms, studying silicic acids in place of their corresponding anions [36, 75-77]. Part of the reason is that it provides information about the formation of silicate aggregates in water, a protic solvent. The disadvantage of this approach is that it introduces additional atoms in the systems, which render more complex on one hand the determination of the optimal geometry for these systems but also the analysis of their vibrational properties with introduction also of 
additional normal modes, tough one could argue that wavenumbers characteristic of $\mathrm{O}-\mathrm{H}$ bonds are quite different from those characteristic of Si-O bonds.

Alternatively, in a few theoretical studies dealing with cluster silicates, the multiply charged anions have been stabilized by placing all around them positive charges (alkali cations) $[23,25]$. This approach is satisfying by some aspects since it deals with silicate anions as in silicate glasses and introduces counter-cations which are also present in real silicates. Nonetheless, the question of the position of these cations can be asked, in particular to avoid coupling with the normal modes of the $\mathrm{Si}-\mathrm{O}$ part. In addition, in a cluster model, it is difficult to ensure the whished high coordination for the counter-cations, what could affect in response the geometry of the silicate part.

Thus, in this work, it was decided to adopt another strategy and to replace in silicate clusters the non-bridging oxygen atoms $\left(\mathrm{O}_{\mathrm{nb}}\right)^{--}$those holding one negative charge -- by fluorine atoms. Indeed, a fluorine atom is isoelectronic to an oxygen mono-anion. Thus the same electrons, meaning coming from the same atomic orbitals, are involved in a Si-F bond and in a $\mathrm{Si}^{-}$bond. And replacing all the non-bridging oxygens by fluorines in silicate clusters render neutral systems where the problem of electronic instability has disappeared. Thus it can be expected that from the electronic point of view, small $\mathrm{Si}_{x} \mathrm{O}_{y} \mathrm{~F}_{z}$ clusters are good models for extended negatively charged silicates in solids. This was noticed by Ignatyev and Sundius in their study of the theoretical force field of $\mathrm{F}_{3} \mathrm{SiOSiF}_{3}[78]$; nevertheless, to the best of our knowledge, replacing NBO by fluorines in silicate clusters is a strategy which has never been used to mimic the behavior of solid silicates of different $Q_{n}$ coordination types. Nonetheless, the advantages of the $\mathrm{O}^{-} / \mathrm{F}$ substitution have to be differentiating; $\mathrm{F}$ and $\mathrm{O}^{-}$ differ by their nuclei: the $\mathrm{F}$ nucleus with one proton more compared to the $\mathrm{O}$ nucleus attracts more its electrons. This is at the origin of $\mathrm{F}$ having a higher electronegativity and a smaller atomic radius than $\mathrm{O}$. Therefore the $\mathrm{Si}-\mathrm{F}$ bond is slightly shorter $(1.60 \AA)$ than the $\mathrm{Si}-\mathrm{O}$ bond 
(1.63 $\AA$ ), and in consequence stronger $(576 \mathrm{~kJ} / \mathrm{mol}$ vs. $452 \mathrm{~kJ} / \mathrm{mol})$. Thus, in a Raman spectrum, it can be expected that the wavenumber associated with a normal mode involving $\mathrm{Si}-\mathrm{F}$ bonds is slightly higher than the same one with $\mathrm{Si}^{-} \mathrm{O}^{-}$bonds. This is however counterbalanced to some extent by the fact that a fluorine atom is heavier than an oxygen atom (19 amu vs. $16 \mathrm{amu}$ ). Despite this partial compensation, it was chosen to replace the mass of fluorines by that of an oxygen atom in the computation of the normal modes of the clusters, in order to produce normal atomic displacements as close as possible to those encountered with oxygen atoms. This is important for the consequences of the $\mathrm{O}^{-} / \mathrm{F}$ substitution on Raman intensities. Indeed, if $\mathrm{F}$ is clearly less polarizable than $\mathrm{O}^{-}$, since the $\mathrm{Si}-\mathrm{F}$ and $\mathrm{Si}^{-} \mathrm{O}^{-}$bond are very similar from the electronic point of view, as we just said, the polarizability response to a same modification of geometry (i.e. same normal atomic displacement) should be similar too.

\subsection{Systems considered in the study}

Ten silicate clusters have been considered to mimic the different $Q_{n}$ coordination types encountered in solid silicates. They are sketched in Figure 2. Among them, 7 are characterized by $\mathrm{Si}$ atoms having all the same environment: $\mathrm{SiF}_{4}$ which has to be considered as a model for nesosilicates $\left(Q_{0}\right), \mathrm{Si}_{2} \mathrm{OF}_{6}$, a model for sorosilicates $\left(Q_{1}\right), \mathrm{Si}_{3} \mathrm{O}_{3} \mathrm{~F}_{6}, \mathrm{Si}_{4} \mathrm{O}_{4} \mathrm{~F}_{8}$ and $\mathrm{Si}_{6} \mathrm{O}_{6} \mathrm{~F}_{12}$, three cyclic models for cyclosilicates-- and to some extent for inosilicates -- $\left(Q_{2}\right)$ and $\mathrm{Si}_{4} \mathrm{O}_{6} \mathrm{~F}_{4}$ and $\mathrm{Si}_{8} \mathrm{O}_{12} \mathrm{~F}_{8}$, two multicyclic models for phyllosilicates $\left(Q_{3}\right)$. The cyclic and multicyclic clusters show some ring tension; nonetheless, it is not unphysical since $\mathrm{Si}_{3} \mathrm{O}_{9}{ }^{6-}, \mathrm{Si}_{4} \mathrm{O}_{12}{ }^{8-}$ and $\mathrm{Si}_{6} \mathrm{O}_{18}{ }^{12-}$ rings are observed in cyclosilicates, and some structural similarities can be observed between $\mathrm{Si}_{8} \mathrm{O}_{12} \mathrm{~F}_{8}$ where each $\mathrm{Si}$ is involved into three " $\mathrm{Si}_{4} \mathrm{O}_{4}$ " rings, and coesite, a silica crystalline polymorph where each $\mathrm{Si}$ is involved into two " $\mathrm{Si}_{4} \mathrm{O}_{4}$ " rings sharing one edge.

The 3 remaining silicate clusters are characterized by silicon ions of two $Q_{n}$ coordination types: $\mathrm{Si}_{3} \mathrm{O}_{2} \mathrm{~F}_{8}$ and $\mathrm{Si}_{4} \mathrm{O}_{3} \mathrm{~F}_{10}$ mix $Q_{1}$ and $Q_{2}$ silicon ions, while $\mathrm{Si}_{5} \mathrm{O}_{6} \mathrm{~F}_{8}$ mixes $Q_{2}$ 
and $Q_{4}$ silicon ions. Both $\mathrm{Si}_{3} \mathrm{O}_{2} \mathrm{~F}_{8}$ and $\mathrm{Si}_{4} \mathrm{O}_{3} \mathrm{~F}_{10}$ can be viewed as models for inosilicates, and $\mathrm{Si}_{5} \mathrm{O}_{6} \mathrm{~F}_{8}$ is the only example among the clusters considered in the study showing a $Q_{4} \mathrm{Si}$; it results from the impossibility to form a non-periodic silicate with only $Q_{4}$ silicon ions.<smiles>F[Si](F)(F)CCS</smiles><smiles>F[Si](F)(F)O[Si](F)(F)F</smiles>

$\mathrm{SiF}_{4}\left(\mathbf{Q}_{0}\right)$

$\mathrm{Si}_{2} \mathrm{OF}_{6}\left(\mathrm{Q}_{1}\right)$<smiles>F[Si]1(F)O[Si](F)(F)O[Si](F)(F)O1</smiles>

$\mathrm{Si}_{3} \mathrm{O}_{3} \mathrm{~F}_{6}\left(\mathrm{a}_{2}\right)$

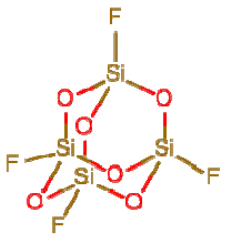

$\mathrm{Si}_{4} \mathrm{O}_{6} \mathrm{~F}_{4}\left(\mathrm{Q}_{3}\right)$<smiles>FC(F)(F)O[Si](F)(F)O[Si](F)(F)F</smiles>

$\mathrm{Si}_{3} \mathrm{O}_{2} \mathrm{~F}_{8}\left(\mathrm{Q}_{1}\right.$ and $\left.\mathrm{Q}_{2}\right)$<smiles>FC1(F)O[Si](F)(F)O[Si](F)(F)O[Si](F)(F)O1</smiles>

$\mathrm{Si}_{4} \mathrm{O}_{4} \mathrm{~F}_{8}\left(\mathrm{Q}_{2}\right)$

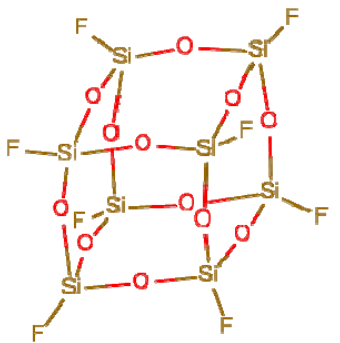

$\mathrm{Si}_{8} \mathrm{O}_{12} \mathrm{~F}_{8}\left(\mathrm{Q}_{3}\right)$<smiles>FC(F)(F)O[Si](F)(F)O[Si](F)(F)F</smiles>

$\mathrm{Si}_{4} \mathrm{O}_{3} \mathrm{~F}_{10}\left(\mathrm{Q}_{1}\right.$ and $\left.\mathrm{Q}_{2}\right)$<smiles>F[Si]1(F)O[Si](F)(F)O[Si](F)(F)O[Si](F)(F)O[Si](F)(F)O[Si](F)(F)O[Si](F)(F)O1</smiles>

$\mathrm{Si}_{6} \mathrm{O}_{6} \mathrm{~F}_{12}\left(\mathrm{Q}_{2}\right)$<smiles>F[Si]1(F)O[Si](F)(F)O[Si]2(O1)O[Si](F)(F)O[Si](F)(F)O2</smiles>

$\mathrm{Si}_{5} \mathrm{O}_{6} \mathrm{~F}_{8}\left(\mathrm{Q}_{2}\right.$ and $\left.\mathrm{Q}_{4}\right)$

Fig 2. Sketch of the ten structural models considered in the study. Seven models over the ten are characterized by $\mathrm{Si}$ atoms having all the same coordination type in one molecule: the $\mathrm{SiF}_{4}$ and $\mathrm{Si}_{2} \mathrm{OF}_{6}$ molecules are models for nesosilicates $\left(Q_{0}\right)$ and sorosilicates $\left(Q_{1}\right)$ respectively; the three monocyclic $\mathrm{Si}_{3} \mathrm{O}_{3} \mathrm{~F}_{6}, \mathrm{Si}_{4} \mathrm{O}_{4} \mathrm{~F}_{8}$ and $\mathrm{Si}_{6} \mathrm{O}_{6} \mathrm{~F}_{12}$ molecules are models for cyclo- and inosilicates $\left(Q_{2}\right)$; the multicyclic clusters of $\mathrm{Si}_{4} \mathrm{O}_{6} \mathrm{~F}_{4}$ and $\mathrm{Si}_{8} \mathrm{O}_{12} \mathrm{~F}_{8}$ stoichiometry constitute models for phyllosilicates $\left(Q_{3}\right)$. The three remaining clusters -- $\mathrm{Si}_{3} \mathrm{O}_{2} \mathrm{~F}_{8}, \mathrm{Si}_{4} \mathrm{O}_{3} \mathrm{~F}_{10}$ and $\mathrm{Si}_{5} \mathrm{O}_{6} \mathrm{~F}_{8}$ -- are characterized by $S i$ atoms having different coordination types in the same chemical system. $\mathrm{Si}_{5} \mathrm{O}_{6} \mathrm{~F}_{8}$ is the only one over the ten having a Si atom with $Q_{4}$ coordination type; as such, it can be useful to model tektosilicates.

With these 10 silicate clusters, the effect of polymerization on the Raman spectra can be studied in different ways. The $\left(\mathrm{SiF}_{4} \rightarrow \mathrm{Si}_{2} \mathrm{OF}_{6} \rightarrow \mathrm{Si}_{3} \mathrm{O}_{2} \mathrm{~F}_{8} \rightarrow \mathrm{Si}_{4} \mathrm{O}_{3} \mathrm{~F}_{10}\right)$ sequence can be viewed as a way to go progressively from $0 \mathrm{D}$ to $1 \mathrm{D}$ polymerization of " $\mathrm{SiO}_{4}$ " tetrahedra in 
silicates (going from nesosilicates to chain inosilicates via sorosilicates). The $\left(\mathrm{SiF}_{4} \rightarrow \mathrm{Si}_{2} \mathrm{OF}_{6}\right.$ $\left.\rightarrow \mathrm{Si}_{3} \mathrm{O}_{3} \mathrm{~F}_{6} \rightarrow \mathrm{Si}_{4} \mathrm{O}_{6} \mathrm{~F}_{4}\right)$ sequence allows going from $Q_{0}$, to $Q_{1}$ to $Q_{2}$ to $Q_{3}$ coordination with in each case the minimal amount of $\mathrm{Si}$ atoms, having all the same environment. The $\left(\mathrm{SiF}_{4} \rightarrow\right.$ $\left.\mathrm{Si}_{2} \mathrm{OF}_{6} \rightarrow \mathrm{Si}_{3} \mathrm{O}_{3} \mathrm{~F}_{6} \rightarrow \mathrm{Si}_{4} \mathrm{O}_{6} \mathrm{~F}_{4}\right)$ sequence can be viewed as the successive duplications of $\mathrm{SiF}_{4}$ in the three spatial dimensions.

\section{Computational details}

\subsection{Ab initio calculations}

The electronic structures of all the clusters sketched on Figure 2 have been computed by density functional theory (DFT), using the B3LYP hybrid functional, which has proven to constitute a good cost-effective choice for the prediction of molecular vibrational properties [79]. It is also worth noting that B3LYP is currently considered has one of the best methods for the calculation of vibrational spectra of extended silicates (assumption based on frequency-based criteria) [80-83]. It was employed in conjunction with the def2-TZVPD basis set, developed by Rappoport and Furche [84] by diffuse augmentation of the Karlsruhe segmented contracted basis set of triple-zeta valence quality def2-TZVP [85]. Thus the def2TZVPD basis set includes $(2 \mathrm{~d} 1 \mathrm{f})$ polarization functions plus (1s1d) diffuse functions for Si atoms and (2d1f) polarization functions plus (1s1p1d) diffuse functions for $\mathrm{O}$ and $\mathrm{F}$ atoms. It has the advantage to have been designed to give good computed molecular properties such as polarizabilities, whose responses to a modification of geometry are used to compute Raman activities. Its parameters for Si, O and F were found on the EMSL Basis Set Library [86, 87]. All the calculations have been performed using either the Gaussian 03 [88] or the Gaussian 09 [89] program. 
In a first step, the geometries of all the clusters were optimized in vacuum. Then, frequency calculations were performed using the same computational methodology. The objective was double: $(i)$ check that the geometries obtained corresponded to stable equilibriums on the corresponding potential energy surfaces and (ii) compute the normal modes. The freq=readisotopes option was used in order to convert the mass of $\mathrm{F}$ atoms into that of $\mathrm{O}$ ones.

\subsection{Computation of Raman intensities}

In the Placzek's polarizability theory, the non-resonant Stokes Raman intensity of the $k^{\text {th }}$ normal vibrational mode of a given system is given by [90]:

$$
I_{k}=N \frac{\left(v_{0}-v_{k}\right)^{4} P}{v_{k}\left(1-\exp \left(\frac{-h c v_{k}}{k_{B} T}\right)\right)} S_{k}
$$

where $N$ is a constant, $v_{0}$ the exciting laser wavenumber, $v_{k}$ the wavenumber of the $k^{\text {th }}$ normal mode, $P$ the exciting laser irradiance, and $S_{k}$ the Raman activity associated to the $k^{\text {th }}$ normal mode (given by Gaussian during a frequency calculation).

The ratio between two band intensities $I_{k}$ and $I_{l}$ can then be expressed as:

$$
\frac{I_{k}}{I_{l}}=\left(\frac{\left(v_{0}-v_{k}\right)}{\left(v_{0}-v_{l}\right)}\right)^{4} \cdot \frac{\left(1-\exp \left(\frac{-h c v_{l}}{k_{B} T}\right)\right)}{\left(1-\exp \left(\frac{-h c v_{k}}{k_{B} T}\right)\right)} \cdot \frac{v_{l}}{v_{k}} \cdot \frac{S_{k}}{S_{l}}
$$

It is then independent of the constant $N$ and the laser irradiance $P$.

Two exciting laser wavenumbers, frequently used in Raman spectroscopy of silicates, will be considered in our computations: $532 \mathrm{~nm}$ and $780 \mathrm{~nm}$. It will allow quantifying influence of 
$v_{0}$ on the Ip index. However, it can be anticipated that the effect of $v_{0}$ will be quite small since in the limit $v_{0} \gg v_{k}$ expression (3) simplifies into expression (4) which is independent from $v_{0}$ :

$$
\frac{I_{k}}{I_{l}}=\frac{\left(1-\exp \left(\frac{-h c v_{l}}{k_{B} T}\right)\right)}{\left(1-\exp \left(\frac{-h c v_{k}}{k_{B} T}\right)\right)} \cdot \frac{v_{l}}{v_{k}} \cdot \frac{S_{k}}{S_{l}}
$$

\subsection{Analysis of the stretching character}

The Ip polymerization index defined in equation (1) is based on the separation of stretching and bending modes on wavenumbers criteria. In order to compute the Ip index for the structural models considered in this study, which are characterized by discrete modes rather than vibrational bands, it was necessary to evaluate the stretching character of these. In that purpose, we made use of the stretching character index defined by Zotov and coworkers in their computational study of silicate glasses [64]. As such, in a given chemical system, the stretching character $P_{k}^{s t r}$ of the $k^{t h}$ normal mode is defined as:

$$
P_{k}^{s t r}=\frac{\sum_{i-j b o n d s}\left|\left(u_{k}^{i}-u_{k}^{j}\right) \cdot r_{i j}\right|}{\sum_{i-j b o n d s}\left|u_{k}^{i}-u_{k}^{j}\right|}
$$

with $r_{i j}$ a unit vector along the bond between atom $i$ and atom $j$, and $u_{k}^{l}$ the displacement of atom $l$ in mode $k$.

By definition, $P_{k}^{s t r}$ takes on values between 0 (pure bending character) and 1 (pure stretching character). 


\section{Results}

\subsection{Validity of the $\mathrm{O}^{-}$/ $\mathrm{F}$ substitution}

As mentioned earlier, one of the elements on which is based the present study is the replacement, in the clusters considered, of non-bridging oxygen atoms by fluorine ones having the mass of an oxygen, in order to avoid dealing with negatively charged systems. To validate this strategy, we compared the normal modes of $\mathrm{SiF}_{4}$ with those observed for the isolated $\mathrm{SiO}_{4}{ }^{4-}$ tetrahedral anions in nesosilicates $\left(Q_{0}\right)$.

In Table 1 the wavenumbers associated with the computed normal modes of $\mathrm{SiF}_{4}$ are reported, either with a mass of $18.99984 \mathrm{amu}$ (that of an F atom) or of $15.99940 \mathrm{amu}$ (that of an $\mathrm{O}$ atom) for fluorines. With the normal mass of fluorine atoms, wavenumbers are slightly underestimated -- by $10-20 \mathrm{~cm}^{-1}$-- with respect to the experimental ones for $\mathrm{SiF}_{4}$, in agreement with what is described in the literature for similar computational methods [91]. After mass correction, since oxygen atoms are lighter than fluorine ones, wavenumbers are logically increased -- by about $25 \mathrm{~cm}^{-1}$ for bending modes and by $50-70 \mathrm{~cm}^{-1}$ for stretching modes. As a result, the symmetric stretching mode, which gives rise to a very intense signal in Raman spectra of nesosilicates, appears at $853 \mathrm{~cm}^{-1}$, in very close agreement with experimental observations $\left(\sim 850 \mathrm{~cm}^{-1}\right)$. This supports the strategy chosen to replace nonbridging oxygen atoms by fluorine ones in our structural models of silicates.

Despite this good agreement, it has to be noted that since Si-F bonds are stronger than Si-O bonds, wavenumbers computed after mass correction are expected to be overestimated with respect to their corresponding values in nesosilicates. Thus it has to be specified that it is not expected to be able to extrapolate quantitative data for solid silicates from results obtained for the clusters studied in this work. But it appears reasonable to think that the qualitative 
evolution of the Ip index with the degree of polymerization will be similar for the clusters considered in the study and for solid silicates, and that in addition, the origin will be the same in both cases.

Table 1. Computed wavenumbers $\left(\mathrm{cm}^{-1}\right)$ of the normal modes of SiF 4 . From the optimized geometry of the $\mathrm{SiF}_{4}$ molecule, the frequency calculation has been performed either with a mass of 18.99984 amu (before mass correction) or with a mass of 15.99940 amu (after mass correction) for the $F$ atoms. For comparison, the experimentally observed wavenumbers for the $\mathrm{SiF}_{4}$ molecule are also given.

\begin{tabular}{cccc}
\hline \multirow{2}{*}{ Normal mode } & \multicolumn{3}{c}{ Wavenumber $\left(\mathrm{cm}^{-1}\right)$} \\
\cline { 2 - 4 } & \multirow{2}{*}{ Before mass correction } & $\begin{array}{c}\text { Experimentally observed } \\
{[92]}\end{array}$ & After mass correction \\
\hline \hline Stretch. (asym.) & 1014 & 1032 & 1059 \\
Stretch. (sym.) & $\mathbf{7 8 3}$ & $\mathbf{8 0 0}$ & $\mathbf{8 5 3}$ \\
Bend. (asym.) & 379 & 389 & 405 \\
Bend. (sym.) & 257 & 268 & 280 \\
\hline
\end{tabular}

\subsection{A model able to reproduce the variability of the Si-O-Si angle}

Interestingly, the Si-O-Si angles resulting from the optimized geometries of the 10 clusters vary from $\sim 120^{\circ}$ to $\sim 180^{\circ}$, just as in silicate glasses (see Figure 3 ). Clearly, the value of the angle results mainly from the geometrical constraints such as the number of rings in which the Si atoms are involved, and their size. Indeed, if we compare the Si-O-Si angle values for the three monocyclic clusters $\mathrm{Si}_{3} \mathrm{O}_{3} \mathrm{~F}_{6}, \mathrm{Si}_{4} \mathrm{O}_{4} \mathrm{~F}_{8}$ and $\mathrm{Si}_{6} \mathrm{O}_{6} \mathrm{~F}_{12}$ in which each $\mathrm{Si}$ atom is bonded to 2 fluorines and 2 bridging oxygens, it appears that the Si-O-Si angles close as the ring size decreases, i.e. as the geometrical constraint increases. In addition, if we compare the Si-O-Si angle values for the $\mathrm{Si}_{3} \mathrm{O}_{3} \mathrm{~F}_{6}$ and $\mathrm{Si}_{4} \mathrm{O}_{6} \mathrm{~F}_{4}$ clusters which both involve 6-membered rings but differ by the number of rings in which each $\mathrm{Si}$ atom is involved (1 only for $\mathrm{Si}_{3} \mathrm{O}_{3} \mathrm{~F}_{6}$ but 3 for $\left.\mathrm{Si}_{4} \mathrm{O}_{6} \mathrm{~F}_{4}\right)$, it appears that the $\mathrm{Si}-\mathrm{O}-\mathrm{Si}$ angles close as the number of rings per $\mathrm{Si}$ atom increases. The same trend is observed from comparison of $\mathrm{Si}_{4} \mathrm{O}_{4} \mathrm{~F}_{8}$ and $\mathrm{Si}_{8} \mathrm{O}_{12} \mathrm{~F}_{8}$ clusters. This is another element in support of the idea that geometrical constraints tend to close $\mathrm{Si}-\mathrm{O}-\mathrm{Si}$ angles. For a set of clusters with a given $\mathrm{Q}_{\mathrm{n}}$ coordination type, a measure of these geometrical 
constraints can be inferred from relative total energies of the clusters divided by the number of Si atoms: the higher the energy per $\mathrm{Si}$ atom is, the higher the geometrical constraint in the system is too. Such normalized energies have been calculated and reported in Table S3 in the Supplementary Information from which it can be concluded that as expected the $\mathrm{Si}_{3} \mathrm{O}_{3} \mathrm{~F}_{6}$ cluster is more constrained than the $\mathrm{Si}_{4} \mathrm{O}_{4} \mathrm{~F}_{8}$ one, itself slightly more constrained than the $\mathrm{Si}_{6} \mathrm{O}_{6} \mathrm{~F}_{12}$ cluster. It is also worth noting how destabilized the $\mathrm{Si}_{4} \mathrm{O}_{6} \mathrm{~F}_{4}$ cluster is compared to $\mathrm{Si}_{8} \mathrm{O}_{12} \mathrm{~F}_{8}$, suggesting that $\mathrm{Si}_{4} \mathrm{O}_{6} \mathrm{~F}_{4}$ is particularly constrained. This is most probably at the origin of its quite small $\mathrm{Si}-\mathrm{O}-\mathrm{Si}$ angles and long $\mathrm{Si}-\mathrm{O}$ bonds. Without any geometrical constraint, the Si-O-Si angle tends to be linear (see the $\mathrm{Si}_{2} \mathrm{OF}_{6}$ case in Figure 3). This can be explained by the fact that, since Si-F bonds are quite ionic, antibonding Si-F $\sigma^{*}$ orbitals are mainly localized on the Si part; therefore, a stabilizing in-phase overlap can be established between the $\mathrm{O}$ lone pair hybrids and the Si-F $\sigma^{*}$ orbitals (hyperconjugation). This overlap tends to be better as the $\mathrm{Si}-\mathrm{O}-\mathrm{Si}$ angle opens $[93,94]$. Coming back to the $\mathrm{O}_{\mathrm{nb}} / \mathrm{F}$ substitution used in this work, it is interesting to note that $\mathrm{F}$ being more electronegative than $\mathrm{O}$, the Si-F bond is more ionic than the $\mathrm{Si}-\mathrm{O}$ bond. As such, $\mathrm{Si}-\mathrm{F} \sigma^{*}$ orbitals in the $\mathrm{Si}_{\mathrm{x}} \mathrm{O}_{\mathrm{y}} \mathrm{F}_{\mathrm{z}}$ neutral clusters show a higher $\mathrm{Si}$ contribution than that of $\mathrm{Si}-\mathrm{O} \sigma^{*}$ orbitals in the corresponding $\mathrm{Si}_{\mathrm{x}} \mathrm{O}_{\mathrm{y}+\mathrm{z}}^{\mathrm{z-}}$ anions. Therefore, $\mathrm{Si}-\mathrm{O}-\mathrm{Si}$ angles are expected to be closer to linearity in the case of the neutral clusters than in the corresponding anions.

It can be checked in Figure 3 that there is a linear correlation between the $\mathrm{Si}-\mathrm{O}-\mathrm{Si}$ angle value and the $\mathrm{Si}-\mathrm{O}$ bond length. As the $\mathrm{Si}-\mathrm{O}-\mathrm{Si}$ angle closes, the $\mathrm{Si}-\mathrm{O}$ bond lengthens. It goes from $1.600 \AA$ in $\mathrm{Si}_{2} \mathrm{OF}_{6}$ with a Si-O-Si angle of $173^{\circ}$ to $1.645 \AA$ in $\mathrm{Si}_{4} \mathrm{O}_{6} \mathrm{~F}_{4}$ with a Si-OSi angle of $116^{\circ}$. This trend has been observed experimentally in silica polymorphs and in molecular crystal siloxanes [36]. Quite recently, it has been shown by topological analysis of the electron density and of the Electron Localization Function (ELF), that as the O-Si-O angle value goes from $180^{\circ}$ to $109.5^{\circ}$, the covalent character of the Si-O bond increases, as well as 
the basic character of the siloxane linkage [95]. Simultaneously, the Si-F bond lengths are almost no affected; except for $\mathrm{Si}_{4} \mathrm{O}_{6} \mathrm{~F}_{4}$ where the $\mathrm{Si}-\mathrm{F}$ bonds are quite short $(1.563 \AA)$, they vary from $1.570 \AA$ to $1.575 \AA$ (see Figure S1; Supporting Information).

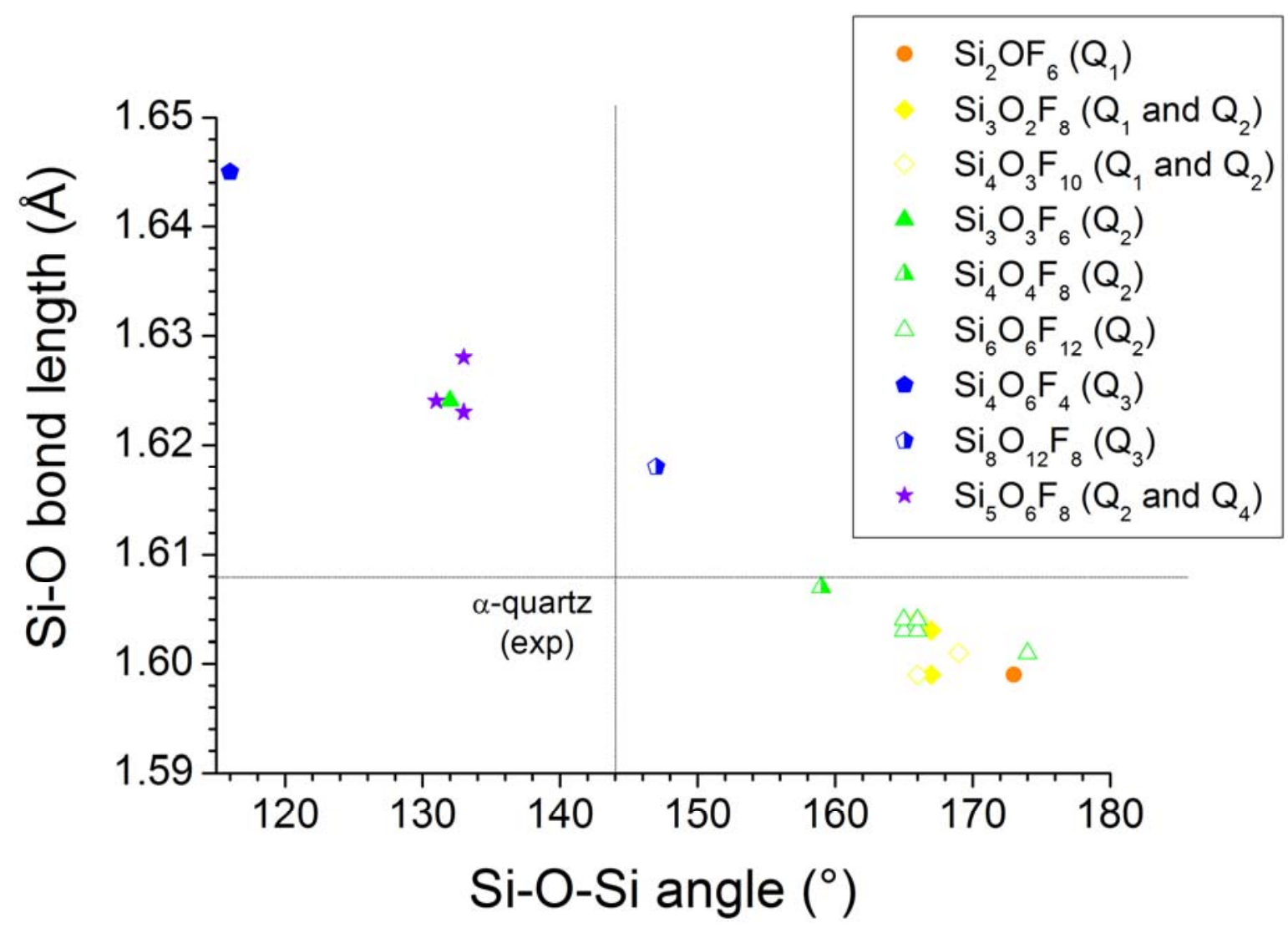

Fig. 3. Correlation between the Si-O bond lengths (in A) and the $\mathrm{Si}-\mathrm{O}$-Si angles $\left(\right.$ in $^{\circ}$ ) in the clusters sketched in Figure 2. For comparison, the experimental values of the Si-O bond length and of the corresponding $\mathrm{Si}-\mathrm{O}$-Si angle in $\alpha$-quartz are indicated.

From this geometrical information, it can be concluded that the clusters considered in this study constitute an ensemble able to reproduce the variability of the structural features of solid silicates. This is an additional element in favor of the strategy chosen to model silicates. 


\subsection{A model which reproduces qualitatively the evolution of Ip with the degree of polymerization}

For each of the 10 clusters sketched in Figure 2, the corresponding normal modes have been computed from the optimized geometry. Figure 4 presents, for each of them, the stretching character of each mode (computed using equation 5) plotted versus the associated wavenumber (after mass correction).

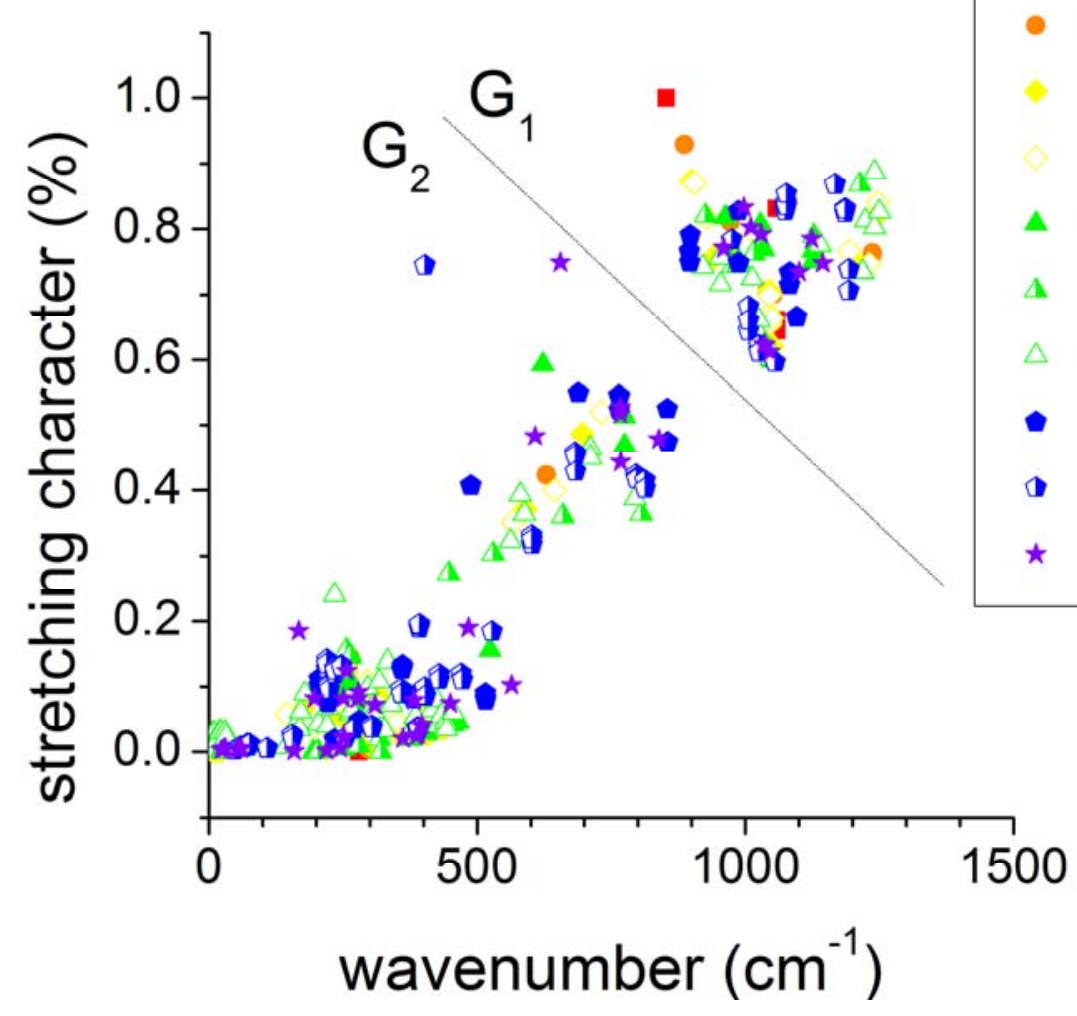

Fig. 4. Stretching character (see equation 5) of the normal modes of the structural models for silicates sketched in Figure 2, plotted against their characteristic wavenumber. The straight dotted line is a guide to the eyes to separate data relative to normal modes belonging to group $G 1$ and those belonging to group G2. 
As expected, the general trend is that the wavenumber characterizing a normal mode increases as its stretching character increases, in agreement with the fact that it is easier to open/close a valence angle than to stretch/compress a chemical bond.

To the naked eye, it appears clearly that normal modes can be divided into (at least) two groups, as symbolized by the straight black line on Figure 4 . We will call $\mathrm{G}_{1}$ the group gathering normal modes with the highest wavenumbers and the highest stretching characters, and $\mathrm{G}_{2}$ the group gathering normal modes with the lowest wavenumbers and the lowest stretching characters. Only two modes (among 411) do not fit perfectly this view, with a too low wavenumber compared to their stretching character. It was decided to affect them to $\mathrm{G}_{2}$ anyway since experimentally calculation of the Ip index comes from decomposition into two groups based on wavenumbers criteria. Group $\mathrm{G}_{1}$ appears quite compact with wavenumbers going from 850 to $1300 \mathrm{~cm}^{-1}$ and stretching characters between 0.6 and 1.0 ; we think it gathers normal modes modeling those giving rise to the band centered around $1000 \mathrm{~cm}^{-1}$ in the Raman spectra of silicate glasses. Group $G_{2}$ involves more dispersion, with wavenumbers going from 0 to $850 \mathrm{~cm}^{-1}$ and stretching character from 0 to 0.6 (if the "abnormal" normal modes are not taken into account). Most probably it includes normal modes modeling those at the origin of the band centered around $500 \mathrm{~cm}^{-1}$ in Raman spectra of silicates, but not only. This is coherent with the fact that graphically group $G_{2}$ seems to be dividable into two subgroups: a first one with intermediate stretching characters and wavenumbers going from 500 to $850 \mathrm{~cm}^{-1}$; and a second one with very small stretching characters $(<0.2)$ and wavenumbers below $500 \mathrm{~cm}^{-1}$.

In Figure 5, the Raman activities of the normal modes of the 10 clusters are plotted versus the corresponding wavenumbers. It appears that the ensemble of 10 clusters gives rise to Raman signals in two wavenumber areas: around $500 \mathrm{~cm}^{-1}$ and around $1000 \mathrm{~cm}^{-1}$, in agreement with the experimental Raman spectra of solid silicates. In addition, it can be 
checked that among normal modes belonging to group $\mathrm{G}_{2}$, those with the lowest wavenumbers and the lowest stretching characters do not contribute significantly to the Raman spectra of the species they are characteristic from. For that reason, and because the separation of G2 into two potential subgroups does not appear clear to define, it was decided to keep the natural separation of clusters normal modes into two groups -- $G_{1}$ and $G_{2}--$ to calculate for each of them a computational Ip index using the following formula:

$$
I p=\frac{I_{G 2}}{I_{G 1}}
$$

with $I_{\mathrm{G} 2}$ the sum of Raman intensities of normal modes belonging to group $\mathrm{G}_{2}$ and $\mathrm{I}_{\mathrm{G} 1}$ the sum of Raman intensities of normal modes belonging to group $\mathrm{G}_{1}$.



Fig. 5. Raman activities of the normal modes of the silicates clusters sketched in Figure 2, plotted against their characteristic wavenumber. The straight dotted line is a guide to the eyes to separate data relative to normal modes belonging to group $G 1$ and those belonging to group $G 2$. 
Figure 6 presents the evolution of this computational Ip index with the average number of bridging oxygen per silicon, a way to render the degree of polymerization of the tetrahedral units. To plot Figure 6, Raman intensities of normal modes have been computed using formula (2). Temperature was chosen to be $298 \mathrm{~K}$, and the exciting laser wavenumber either $532 \mathrm{~nm}$ or $780 \mathrm{~nm}$. It can be checked to these two choices for the exciting wavenumber lead to the same ratio of the intensities, in agreement with the fact that $v_{0}>>v_{k}$. It validates the approximation $v_{0}>>v_{k}$ in equation (4).

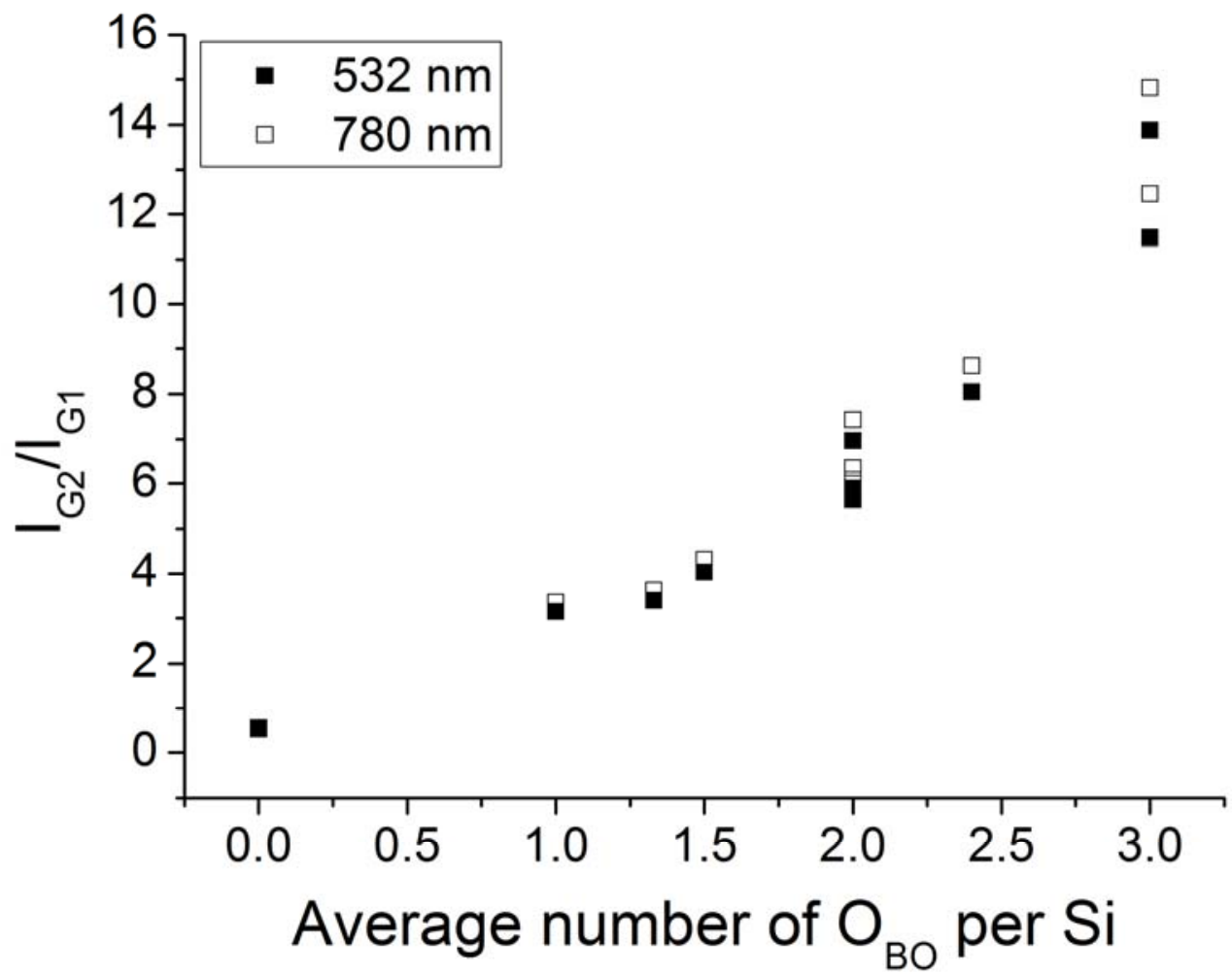

Fig. 6. Ratio $I_{G 2} / I_{G 1}$ computed for two laser exciting wavenumbers $\left(v_{0}=532 \mathrm{~nm}\right.$ and $v_{0}=$ $780 \mathrm{~nm}$ ) and plotted against the average number of bridging oxygen per silicon for the structural models sketched in Figure 2. For each system, $I_{G 2}$ is the sum of the Raman intensities of its normal modes belonging to group $G_{2}$ according to Figure 3 while $I_{G 1}$ is the sum of the Raman intensities of its normal modes belonging to group $G_{1}$. Raman intensities have been calculated using equation 3, from Raman activities and wavenumbers computed by Gaussian 03 and Gaussian 09. 


\section{Discussion}

As observed experimentally for crystalline and amorphous silicates, the computed Ip index for the silicate clusters considered increases as the number of bridging oxygen per silicon increases. The general trend is similar to the experimental one with an Ip index, which varies only slightly from $\mathrm{Q}_{0}$ to $\mathrm{Q}_{2}$ coordination types and then increases more deeply for higher polymerization degrees. It is interesting to note how close to each other are the Ip values of the three $\mathrm{Q}_{2}$ clusters while they are characterized by quite different Si-O-Si angles $\left(132^{\circ}\right.$ for $\mathrm{Si}_{3} \mathrm{O}_{3} \mathrm{~F}_{6}, 159^{\circ}$ for $\mathrm{Si}_{4} \mathrm{O}_{4} \mathrm{~F}_{8}$ and $166^{\circ}$ for $\left.\mathrm{Si}_{6} \mathrm{O}_{6} \mathrm{~F}_{12}\right)$. The same is observed for the two $\mathrm{Q}_{3}$ clusters to a certain extent. And it is remarkable how the Ip values of the clusters showing two kinds of $\mathrm{Q}_{\mathrm{n}}$ coordination types -- $\mathrm{Si}_{3} \mathrm{O}_{2} \mathrm{~F}_{8}, \mathrm{Si}_{4} \mathrm{O}_{3} \mathrm{~F}_{10}$ and $\mathrm{Si}_{5} \mathrm{O}_{6} \mathrm{~F}_{8}$ (average number of $\mathrm{O}_{\mathrm{BO}}$ per Si: $1.33,1.5$ and 2.4 , respectively) -- inserts into the curve. It confirms that the Ip index is really a signature of the $\mathrm{Q}_{\mathrm{n}}$ coordination types and thus a useful tool to gain information about the degree of polymerization of the $\mathrm{SiO}_{4}$ tetrahedra in amorphous silicates. Quantitatively, the values taken on by the $I p$ index for the $\mathrm{Si}_{\mathrm{x}} \mathrm{O}_{\mathrm{y}} \mathrm{F}_{\mathrm{z}}$ clusters are about 4-5 times higher than those obtained for crystalline and amorphous silicates. Nonetheless, the fact that the general trend is well reproduced by the ensemble of clusters considered indicates that it constitutes a suitable model to analyze the origin of the evolution of the Ip index with the degree of polymerization. This will be the subject of another article.

\section{Conclusion}

In this work, an ensemble of ten $\mathrm{Si}_{\mathrm{x}} \mathrm{O}_{\mathrm{y}} \mathrm{F}_{\mathrm{z}}$ clusters with various numbers of $\mathrm{F}$ per $\mathrm{Si}$ has been studied by DFT at the B3LYP/def2-TZVPD level of theory. $\mathrm{Si}_{\mathrm{x}} \mathrm{O}_{\mathrm{y}} \mathrm{F}_{\mathrm{z}}$ clusters can be seen as models for the different classes of silicates on the basis that a fluorine atom is isoelectronic to an oxygen holding one negative charge, as non-bridging oxygens do in silicates. As such, by varying the number of $\mathrm{F}$ atom per $\mathrm{Si}$, the different $Q_{n}$ coordination types existing in 
silicates can be reproduced. Interestingly, the $\mathrm{Si}-\mathrm{O}-\mathrm{Si}$ angle values in the ensemble cover the same range as in amorphous silicates, indicating that the ensemble is able to take into account the variability of geometrical constraints found in amorphous silicates. Normal modes have been calculated for each individual of the ensemble, modifying the mass of fluorine atoms so that it equals that of an oxygen one. As such, evolution of the Ip index with the number of bridging oxygen per silicon behaves similarly to what it does in crystalline and amorphous silicates. This indicates that the ensemble of cluster constitutes a model able to reproduce the effect of $\mathrm{SiO}_{4}$-polymerization on the Raman intensities in silicates and aluminosilicates. The approach adopted in this work is obviously transferable to other oxides (borates, phosphates, sulfates ...) and one can imagine constructing models for other glasses on the same basis: substitution of $\mathrm{O}-$ by $\mathrm{F}$ and then mass correction of $\mathrm{F}$ atoms. In future work, this model will be used to rationalize this evolution of Ip with the degree of polymerization, what should bring some theoretical support for its use. The effect of $\mathrm{Si} / \mathrm{Al}$ substitution as well as that of presence of heavy cations will be investigated too.

\section{Acknowledgments}

We would like to thank Dr. Bruno Madebène for suggesting modifying the mass of fluorines in frequency calculations. 


\section{References}

[1] N. K. Kildahl, J. Chem. Educ. 72 (1995) 423.

[2] R. J. Gillespie, J. Chem. Educ. 75 (1998) 923.

[3] A. Haaland, T. U. Helgaker, K. Ruud and D. J. Shorokhov, J. Chem. Educ. 77 (2000) 1076.

[4] H. C. Marsmann, Z. Naturforsch. 29B (1974) 495.

[5] K. L. Geisinger and G. V. Gibbs, Phys. Chem. Minerals 7 (1981) 204.

[6] R. L. Mozzi and B. E. Warren, J. Appl. Cryst. 2 (1969) 164.

[7] J. Neuefeind and K. -D. Liss, Ber. Bunsenges. Phys. Chem. 100 (1996) 1341.

[8] T. M. Clark, P. J. Grandinetti, P. Florian and J. F. Stebbins, Phys. Rev. B 70 (2004) 064202 .

[9] N. V. Belov, OcherkipoStrukturnoiMineralogii (Essays on Structural Mineralogy), Nedra, Moscow, 1976.

[10] H. Eckert, Prog. Nucl. Mag. Res. 24 (1992) 159.

[11] P. McMillan, Am. Mineral. 69 (1984) 622.

[12] Ph. Colomban, J. Non-Crys. Solids 323 (2003) 180.

[13] Ph. Colomban and O. Paulsen, J. Am. Ceram. Soc. 88 (2005) 390.

[14] Ph. Colomban, A. Tournié and L. Bellot-Gurlet, J. Raman Spectrosc. 37 (2006) 841.

[15] Ph. Colomban, J. Cultural Heritage 9 (2008) e55.

[16] Ph. Colomban and L.C. Prinsloo in, in: J. Yarwood, R. Douthwaite, S. B. Duckett( Eds), Spectroscopic Properties of Inorganic and Organometallic Compounds, RSC Publishing, The Royal Society of Chemistry, 2009 , pp.128-149.

[17] Ph. Colomban and A. Slodczyk, Optical Materials 31 (2009) 1759.

[18] P. Ricciardi and Ph. Colomban, in : J. M. Chalmers, H. G. M. Edwards, M.Hargreaves (Eds), IR \& Raman spectroscopy in forensic sciences, Wiley \& Sons Ltd, 2012, pp. 469-479.

[19] B. O. Mysen, D. Virgo and F. A. Seifert, Rev. Geophys. Space Phys. 20 (1982) 353.

[20] S. A. Brawer, Phys. Rev. B 11 (1975) 3173.

[21] S. A. Brawer and W. B. White, J. Chem. Phys. 63 (1975) 2421.

[22] S. A. Brawer and W. B. White, J. Non Cryst. Solids 23 (1977) 261.

[23] J.-L. You, G.-C.Jiang, H.-Y.Hou, H. Chen, Y.-Q.Wu and K.-D.Xu, J. Raman Spectrosc. 36 (2005) 237.

[24] D. W. Matson, S. K. Sharma and J. A. Philpotts, J. Non-Cryst. Solids 58 (1983) 323.

[25] T. Furukawa, K. E. Fox and W. B. White, J. Chem. Phys. 75 (1981) 3226.

[26] M. Henry, in B. Silvi and P. D'Arco (eds.), Modelling of Minerals and Silicated Materials, Kluwer Academic Publishers, 2002, pp. 273-334.

[27] Ph. Colomban, A. Tournié M. C. Caggiani and C. Paris, J. Raman Spectrosc. 43 (2012) 1975. 
[28] A. Tournié, Analyse Raman sur site de verres et vitraux anciens : modélisation, procedure, lixiviation et caractérisation ( $\mathrm{PhD}$ dissertation), Université Pierre et Marie Curie, Paris, 2009.

[29] L. De Ferri, D. Bersani, A. Lorenzi, P. Lottici, G. Vezzalini and G. Simon, J. Non-Cryst. Solids 358 (2012) 814.

[30] S. Pérez-Villar, J. Rubio and J. L. Oteo J. Non-Cryst. Solids 354 (2008) 1833.

[31] E. Malchukova, B. Boizot, D. Ghaleb and G. Petite, J. Non-Cryst. Solids 352 (2006) 297.

[32] N. Ollier, T. Charpentier, B. Boizot, G. Wallez and D. Ghaleb, J. Non-Cryst. Solids 341 (2004) 26.

[33] V. Martinez, A. M. Jurdyc, D. Vouagner, C. Martinet and B. Champagnon, J. Non-Cryst. Solids 351 (2005) 2421.

[34] J. Sauer, Chem. Rev. 89 (1989) 199.

[35] K. Jug and T. Bredow, J. Comput. Chem25 . (2004) 1551.

[36] M. D. Newton and G. V. Gibbs, Phys. Chem. Minerals 6 (1980) 221.

[37] B. H. W. S. De Jong and G. E. Brown Jr., Geochim. Cosmochim. Acta 44 (1980) 491.

[38] N. Uchida and M. Shinmei, J. Non-Cryst. Solids 122 (1990) 276.

[39] G. V. Gibbs, E. P. Meagher, M. D. Newton and D. K. Swanson, in M. O'Keefe and A. Navrotsky (Eds), Structure and Bonding in Crystals Vol. 1, Acad. Press., New York, 1981, pp. 195-225.

[40] K. L. Geisinger and G. V. Gibbs, Phys. Chem. Minerals 7 (1981) 204.

[41] J. S. Nicoll, G. V. Gibbs, M.B. BoisenJr, R. T. Downs and K. L. Bartelmehs, Phys. Chem. Minerals. 20 (1994) 617.

[42] G. V. Gibbs, Am. Mineral. 67 (1982) 421.

[43] R. M. Badger, J. Chem. Phys. 2 (1934) 128.

[44] D. R. Herschbach and V. W. Laurie, J. Chem. Phys. 35 (1961) 454.

[45] A. B. Anderson and R. G. Parr, Chem. Phys. Lett. 10 (1971) 293.

[46] P. F. McMillan and A. C. Hess, Phys. Chem. Minerals 17 (1990) 97.

[47] A. N. Lazarev and A. P. Mirgorodsky, Phys. Chem. Minerals 18 (1991) 231.

[48] S. Tsuneyuki, M. Tsukada and H. Aoki, Phys. Rev. Lett. 61 (1988) 869.

[49] R. G. Della Valle and E. Venuti, Chem. Phys. 179 (1994) 411.

[50] B. Guillot and Y. Guissani, Phys. Rev. Lett. 78 (1997) 2401.

[51] V. Kahlenberg, D. Girtler, E. Arroyabe, R. Kaindl and D. M. Többens, Miner. Petrol. 100 (2010) 1.

[52] M. Prencipe, Y. Noel, M. Bruno and R. Dovesi, Am. Mineral. 94 (2009) 986.

[53] E. Arroyabe, R. Kaindl, D. M. Többens and V. Kahlenberg, Inorg. Chem. 48 (2009) 11929.

[54] E. Arroyabe, F. Prechtel, D. M. Többens, R. Kaindl and V. Kahlenberg, Eur. J. Mineral. 23 (2011) 425.

[55] R. Kaindl, D. M. Többens and V. Kahlenberg, J. Raman. Spectrosc. 42 (2011) 78. 
[56] M. Prencipe, J. Raman Spectrosc. (2012) DOI: 10.1002/jrs.4040

[57] J. A. Tossell, Chem. Mater. 6 (1994) 239.

[58] J. A. Tossell, Geochim. Cosmochim. Acta 69 (2005) 283.

[59] D. Sykes and J. D. Kubicki, Geochim. Cosmochim. Acta 57 (1993) 1039.

[60] J. D. Kubicki and E. M. Stopler, Geochim. Cosmochim. Acta 59 (1995) 683.

[61] J. D. Kubicki and D. Sykes, Am. Mineral. 78 (1993) 253.

[62] J. Sarnthein, A. Pasquarello and R. Car, Phys. Rev. Lett. 74 (1995) 4682.

[63] S. N. Taraskin and S. R. Elliott, Phys. Rev. B 56 (1997) 8605.

[64] N. Zotov, I. Ebbsjö, D. Timpel and H. Keppler, Phys. Rev. B 60 (1999) 6383.

[65] L. Giacomazzi, P. Umari and A. Pasquarello, Phys. Rev. B 79 (2009) 064202.

[66] E. Monsivais-Gámez, F. Ruiz and J. R. Martinez, J. Sol-Gel Sci. Technol. 43 (2007) 65.

[67] R. Holomb, M. Veres, V. Mitsa, J. Optoelectron. Adv. Mater. 11 (2009) 917.

[68] D. G. Liakos, E. A. Simandiras, J. Phys. Chem. A 112 (2008) 7881.

[69] A. N. Rosli, N. A. Zabidi, H. A. Kassim and K. N. Shrivastava, J. Clus. Sci. 21 (2010) 197.

[70] M. Wolkenstein, C.R. Acad. Sci. URSS 30 (1941) 791.

[71] M. Eliashevitch and M. Wolkenstein, J. Phys. USSR 9 (1945) 326.

[72] D. A. Long, Proc. R. Soc. London, Ser. A 217 (1953) 203.

[73] A. I. Boldyrev and J. Simons, J. Phys. Chem. 98 (1994) 2298.

[74] G. Roos, F. De Proft and P. Geerlings, J. Phys. Chem. A 109 (2005) 652.

[75] G. J. McIntosh, P.J. Swedlund and T. Söhnel, Phys. Chem. Chem. Phys. 13 (2011) 2314.

[76] B. H. W. S. De Jong and G. E. Brown Jr., Geochim. Et Cosmochim. Acta 44 (1979) 491.

[77] G. Spiekermann, M. Steele-MacInnis, C. Schmidt and S. Jahn, J. Chem. Phys. 136 (2012) 154501.

[78] I.S. Ignatyev and T. R. Sundius, J. Mol. Struct. (Theochem) 343 (1995) 69.

[79] E. E. Zvereva, A. R. Shagidullin and S. A. Katsyuba, J. Phys. Chem. A 115 (2011) 63.

[80] D. M. Többens and V. Kahlenberg, Vibrational Spectroscopy 56 (2011) 265.

[81] R. DeMichelis, B. Civalleri, M. Ferrabone and R. Dovesi, Int. J. Quant. Chem. 110 (2010) 406.

[82] C. M. Zicovich-Wilson, F. Pascale, C. Roetti, V. R. Saunders, R. Orlando and R. Dovesi, J. Comput. Chem. 25 (2004) 1873.

[83] P. Mauro, L. Mantovani, M. Tribaudino, D. Bersani, P. P. Lottici, Eur. J. Mineral. 24 (2012) 457.

[84] D. Rappoport and F. Furche, J. Chem. Phys. 133 (2010) 134105.

[85] F. Weigend and R. Ahlrichs, Phys. Chem. Chem. Phys7 . (2005) 3297.

[86] D. Feller, J. Comput. Chem. 17 (1996) 1571. 
[87] K. L. Schuchardt,B. T. Didier,T. Elsethagen,L. Sun,V. Gurumoorthi,J. Chase,J. Li andT. L. Windus, J. Chem. Inf. Model. 47 (2007) 1045.

[88] Gaussian 03, Revision D.02, M. J. Frisch, G. W. Trucks, H. B. Schlegel, G. E. Scuseria, M. A. Robb, J. R. Cheeseman, J. A. Montgomery, Jr., T. Vreven, K. N. Kudin, J. C. Burant, J. M. Millam, S. S. Iyengar, J. Tomasi, V. Barone, B. Mennucci, M. Cossi, G. Scalmani, N. Rega, G. A. Petersson, H. Nakatsuji, M. Hada, M. Ehara, K. Toyota, R. Fukuda, J. Hasegawa, M. Ishida, T. Nakajima, Y. Honda, O. Kitao, H. Nakai, M. Klene, X. Li, J. E. Knox, H. P. Hratchian, J. B. Cross, V. Bakken, C. Adamo, J. Jaramillo, R. Gomperts, R. E. Stratmann, O. Yazyev, A. J. Austin, R. Cammi, C. Pomelli, J. W. Ochterski, P. Y. Ayala, K. Morokuma, G. A. Voth, P. Salvador, J. J. Dannenberg, V. G. Zakrzewski, S. Dapprich, A. D. Daniels, M. C. Strain, O. Farkas, D. K. Malick, A. D. Rabuck, K. Raghavachari, J. B. Foresman, J. V. Ortiz, Q. Cui, A. G. Baboul, S. Clifford, J. Cioslowski, B. B. Stefanov, G. Liu, A. Liashenko, P. Piskorz, I. Komaromi, R. L. Martin, D. J. Fox, T. Keith, M. A. Al-Laham, C. Y. Peng, A. Nanayakkara, M. Challacombe, P. M. W. Gill, B. Johnson, W. Chen, M. W. Wong, C. Gonzalez, and J. A. Pople, Gaussian, Inc., Wallingford CT, 2004.

[89]Gaussian 09, Revision A.02,M. J. Frisch, G. W. Trucks, H. B. Schlegel, G. E. Scuseria, M. A. Robb, J. R. Cheeseman, G. Scalmani, V. Barone, B. Mennucci, G. A. Petersson, H. Nakatsuji, M. Caricato, X. Li, H. P. Hratchian, A. F. Izmaylov, J. Bloino, G. Zheng, J. L. Sonnenberg, M. Hada, M. Ehara, K. Toyota, R. Fukuda, J. Hasegawa, M. Ishida, T. Nakajima, Y. Honda, O. Kitao, H. Nakai, T. Vreven, J. A. Montgomery, Jr., J. E. Peralta, F. Ogliaro, M. Bearpark, J. J. Heyd, E. Brothers, K. N. Kudin, V. N. Staroverov, R. Kobayashi, J. Normand, K. Raghavachari, A. Rendell, J. C. Burant, S. S. Iyengar, J. Tomasi, M. Cossi, N. Rega, J. M. Millam, M. Klene, J. E. Knox, J. B. Cross, V. Bakken, C. Adamo, J. Jaramillo, R. Gomperts, R. E. Stratmann, O. Yazyev, A. J. Austin, R. Cammi, C. Pomelli, J. W. Ochterski, R. L. Martin, K. Morokuma, V. G. Zakrzewski, G. A. Voth, P. Salvador, J. J. Dannenberg, S. Dapprich, A. D. Daniels, O. Farkas, J. B. Foresman, J. V. Ortiz, J. Cioslowski, and D. J. Fox, Gaussian, Inc., Wallingford CT, 2009.

[90] D. A. Long, Raman Spectroscopy, McGraw-Hill, New York, 1977.

[91] S. K. Ignatov, P.G. Sennikov, A. G. Razuvaev, I.V. Simdyanov and K. G. Tokhadze, Optics and Spectroscopy 90 (2001) 654.

[92] T. Shimanouchi, “Tables of Molecular Vibrational Frequencies, Consolidated Volume 1”, NSRDS NBS-39 (http://www.nist.gov/data/nsrds/NSRDS-NBS-39.pdf)

[93] V. Murashov, J. Mol. Struct. 650 (2003) 141.

[94] G. V. Gibbs, A. F. Wallace, D. F. Cox, R. T. Downs, N. L. Ross and K. M. Rosso, Am. Miner. 94 (2009) 1085.

[95] S. Grabowsky, M. F. Hesse, C. Paulmann, P. Luger and J. Beckmann, Inorg. Chem. 48 (2009) 4384. 